\title{
Anti-epidermal growth factor receptor monoclonal antibody cetuximab inhibits EGFR/HER-2 heterodimerization and activation
}

\author{
DIPA PATEL, RAJIV BASSI, ANDREA HOOPER, MARIE PREWETT, \\ DANIEL J. HICKLIN and XIAOQIANG KANG
}

ImClone Systems Incorporated, New York, NY, USA

Received July 11, 2008; Accepted September 9, 2008

DOI: 10.3892/ijo_00000125

\begin{abstract}
Human carcinomas frequently express one or more members of the epidermal growth factor receptor family. Two family members, epidermal growth factor receptor (EGFR) and c-erbB2/neu (HER2), homodimerize or heterodimerize upon activation with ligand and trigger potent mechanisms of cellular proliferation, differentiation and migration. In this study, we examined the effect of the anti-EGFR monoclonal antibody Erbitux ${ }^{\mathrm{TM}}$ (cetuximab) on human tumor cells expressing both EGFR and HER2. Investigation of the effect of cetuximab on the activation of EGFR-EGFR, EGFR-HER2 and HER2-HER 2 homodimers and heterodimers was conducted using the NCI-N87 human gastric carcinoma cell line. Treatment of NCI-N87 cells with cetuximab completely inhibited formation of EGFR-EGFR homodimers and EGFRHER2 heterodimers. Activation of HER2-HER2 homodimers was not appreciably stimulated by exogenous ligand and was not inhibited by cetuximab treatment. Furthermore, cetuximab inhibited EGF-induced EGFR and HER2 phosphorylation in CAL27, NCI-H226 and NCI-N87 cells. The activation of downstream signaling molecules such as AKT, MAPK and STAT-3 were also inhibited by cetuximab in these cells. To examine the effect of cetuximab on the growth of tumors in vivo, athymic mice bearing established NCI-N87 or CAL27 xenografts were treated with cetuximab (1 mg, i.p., q3d). The growth of NCI-N87 and CAL27 tumors was significantly inhibited with cetuximab therapy compared to the control groups $(\mathrm{p}<0.0001$ in both cases). In the CAL27 xenograft model, tumor growth inhibition by cetuximab treatment was
\end{abstract}

Correspondence to: Dr Xiaoqiang Kang, Department of Immunology, ImClone Systems Incorporated, 180 Varick Street, New York, NY 10014, USA

E-mail: xkang@imclone.com

Abbreviations: EGF, epidermal growth factor; EGFR, epidermal growth factor receptor; TK, tyrosine kinase; NSCLC, non-small cell lung cancer; DTSSP, 3,3'-dithiobis(sulfosuccinimidylpropionate); MAPK, mitogen-activated protein kinase; AKT, protein kinase B

Key words: ErbB family, epidermal growth factor receptor, Her2, antibody, dimer similar to that by cetuximab and trastuzumab combination treatment. Immunohistological analysis of cetuximab-treated tumors showed a decrease in EGFR-HER2 signaling and reduced tumor cell proliferation. These results suggest that cetuximab may be useful in the treatment of carcinomas coexpressing EGFR and HER2.

\section{Introduction}

The ErbB family belongs to the type I receptor tyrosine kinases and includes EGFR (HER1, ErbB1), Her2/neu (ErbB2), ErbB3 (HER3) and ErbB4 (HER4). These receptors share $40-50 \%$ homology in amino acids and a similar structural organization. They contain an extracellular binding domain, a transmembrane domain, and an intracellular protein tyrosine kinase (TK) domain. The exception is HER3, which has an inactive intracellular TK domain (1). Of these four members of the ErbB family, EGFR and HER2 have been implicated to play oncogenic roles in human tumors (2). Overexpression of EGFR has been observed in colorectal, glioblastoma, gastric, breast, ovarian and squamous cell carcinomas (3). EGFR overexpression has been shown to contribute to cell transformation, proliferation and mitogenesis $(4,5)$. Poor prognosis and short survival were correlated with EGFR expression in cancer patients (6). Overexpression of HER2 has also been observed in many types of cancer. HER 2 is overexpressed in $30 \%$ of breast and ovarian cancer and is correlated with metastasis, early relapse and poor prognosis (7-10). Amplification of the HER2 gene also was reported in a variety of cancers including prostate, stomach and lung (11). Moreover, tumors that co-express EGFR and HER2 appear to result in a less favorable patient prognosis than tumors that express either receptor alone (12), indicating co-operation of the two receptors in tumor progression.

ErbB family members are activated by various ligands except HER2, which may not have physiological ligands. Upon ligand stimulation, ErbB family members form homodimers or heterodimers and undergo receptor phosphorylation. Although HER2 is unable to bind to any ligand, it can form heterodimers with other members of the ErbB family particularly EGFR and HER3 and therefore becomes activated (13-15). This is supported by the evidence that EGF can only activate HER2 when EGFR is present in the same cells (16). The receptor dimerization results in conformational change 
and activation of the kinase domain leading to autophosphorylation and the induction of various signal transduction cascades. It has been reported that EGFR and HER2 activate various common signaling pathways including Ras/Raf/ MEK/ERK and PI3K/AKT (14). Activation of MAPK can stimulate cell division and proliferation (17-19), and the PI3K/ AKT pathway plays important roles in cell survival $(20,21)$. Both pathways are important in the development and maintenance of tumor cells, suggesting EGFR and HER2 are therapeutic targets, and inhibition of both receptors should be pursued in tumors expressing both receptors.

Current EGFR- and HER2-based targeted therapies of cancer include the use of monoclonal antibodies and small molecule inhibitors. Cetuximab (Erbitux), a human-mouse chimeric monoclonal antibody to EGFR, is able to block EGFor TGF- $\alpha$-induced EGFR phosphorylation and activation, which leads to inhibition of proliferation and growth of tumor cells in vitro $(3,22)$. The downstream AKT and MAPK activation by EGF is often inhibited with cetuximab coincubation (23). Cetuximab has been shown to effectively inhibit the growth of tumors expressing EGFR in animals and cancer patients. The range of tumor cell lines inhibited by cetuximab is rather broad. Almost all EGFR-positive tumor cells can be targets for cetuximab, such as colorectal, lung, prostate, head and neck, ovarian, esophagus, thyroid, liver and pancreatic carcinomas (24-26). To date, cetuximab has been approved for patients with colorectal and head and neck cancer. X-ray crystal structure of the antigen-binding (Fab) fragment from cetuximab in complex with the soluble extracellular region of EGFR (sEGFR) has revealed the mechanism by which cetuximab inhibits EGFR activation (27). Cetuximab interacts exclusively with domain III of sEGFR, partially occluding the ligand-binding region on this domain and sterically preventing the receptor from adopting the extended conformation required for dimerization. This suggests that cetuximab disrupts both ligand binding and receptor dimerization. Trastuzumab (Herceptin), a humanized monoclonal antibody that targets the ectodomain of HER2, was approved for the treatment of breast cancer patients and was shown to prolong the survival of metastatic breast cancer patients with tumors expressing HER2 (28). Trastuzumab has been shown to be able to block HER2 activation and its signaling pathway (29).

In this study, we examined the effect of cetuximab on the formation of EGFR-EGFR, EGFR-HER2 and HER2-HER2 homodimers and heterodimers in human tumor cells expressing both EGFR and HER2. We found that cetuximab binds to the EGF receptor and inhibits EGFR-EGFR homodimerization and EGFR-HER2 heterodimerization. EGFR and HER2 receptor phosphorylation and subsequent signal cascades also were inhibited by cetuximab. Furthermore, cetuximab reduced HER2 phosphorylation in vivo and inhibited the growth of tumors expressing EGFR and HER2.

\section{Materials and methods}

Cell lines. EGFR- and HER2-positive NCI-N87 gastric carcinoma cells and NCI-H226 non-small cell lung cancer (NSCLC) cells were maintained in RPMI-1640 media (Invitrogen, CA) supplemented with 10\% heat inactivated fetal bovine serum (FBS) (Hyclone, UT). Squamous carcinoma CAL27 cells were maintained in DMEM (Invitrogen) supplemented with $10 \%$ FBS. Cell lines were obtained from the American Type Culture Collection (Manassas, VA).

Monoclonal antibodies. Anti-EGFR monoclonal antibody cetuximab (Erbitux) was produced by ImClone Systems Incorporated manufacturing facility (Somerville, NJ). AntiHER2 monoclonal antibody trastuzumab (Herceptin) was produced by Genentech Incorporated (Genentech Inc., CA). Other antibodies used were anti-HER2 Ab10 (Neomarkers, CA), anti-EGFR Ab11 (Neomarkers), anti-phospho-HER2 Ab -2241 and -2247 (Cell Signaling Technology, MA), antiphospho-EGFR Ab (Upstate Biotechnology, NY). Antibodies to p-AKT (Ser473, Thr308), AKT, p-44/42 ERK 1/2 (Thr202/Tyr204), Erk 1/2 and p-STAT3 (Ser727, Tyr705) were purchased from Cell Signaling Technology.

Flow cytometry. Cells $\left(1 \times 10^{6}\right)$ were stained for $1 \mathrm{~h}$ with $10 \mu \mathrm{g} /$ $\mathrm{ml}$ anti-EGFR antibody cetuximab or with anti-HER2 antibody trastuzumab at $4^{\circ} \mathrm{C}$. Cells were washed and labeled with FITC anti-human secondary antibody (Biosource Intl., CA) and analyzed using an Epics XL flow cytometer (Coulter, FL).

Dimerization analysis. NCI-N87 cells were serum starved overnight, washed with cold PBS containing $0.1 \mathrm{mM}$ $\mathrm{Na}_{2} \mathrm{VO}_{4}$, and treated with $20 \mu \mathrm{g} / \mathrm{ml}$ cetuximab or human IgG for $30 \mathrm{~min}$ at $37^{\circ} \mathrm{C}$, followed by stimulation with $100 \mathrm{ng} / \mathrm{ml}$ EGF ligand for $10 \mathrm{~min}$ at $37^{\circ} \mathrm{C}$. Cells were treated with crosslinking reagent DTSSP according to the manufacturer's protocol (Sigma, MO), washed twice with cold PBS/50 nm $\mathrm{Na}_{2} \mathrm{VO}_{4}$ and lysed with lysis buffer containing $50 \mathrm{mM}$ Tris (pH 7.5), $150 \mathrm{mM} \mathrm{NaCl}, 1 \%$ Triton X-100, 0.25\% deoxycholic acid, $1 \mathrm{mM}$ PMSF, $0.1 \mathrm{mM} \mathrm{Na} \mathrm{VO}_{4}$ and $1 \mathrm{mM} \mathrm{NaF}$. The lysates were then cleared by centrifugation. To detect EGFR-EGFR homodimers, lysates were immunoprecipitated with $10 \mu \mathrm{g} / \mathrm{ml}$ anti-HER2 antibody $\mathrm{Ab} 10$ for $1 \mathrm{~h}$ at $4^{\circ} \mathrm{C}$ followed by Protein $\mathrm{A} / \mathrm{G}$ beads for $1 \mathrm{~h}$ at $4^{\circ} \mathrm{C}$ to remove all EGFR-HER2 and HER2-HER2 dimers from the lysates. The HER2-cleared lysates were subjected to SDS-PAGE, transferred to PVDF membranes and probed with anti-EGFR mAb Ab11. To detect the EGFR-HER2 heterodimer, the lysates were immunoprecipitated with $10 \mu \mathrm{g} / \mathrm{ml}$ anti-EGFR antibody cetuximab for $1 \mathrm{~h}$ at $4^{\circ} \mathrm{C}$ followed by Protein $\mathrm{A} / \mathrm{G}$ beads for $1 \mathrm{~h}$ at $4^{\circ} \mathrm{C}$. The immunoprecipitates were then subjected to Western blot analysis as described above probing with anti-HER2 antibody Ab10. To detect HER2-HER2 homodimers, the lysates were immunoprecipitated with $10 \mu \mathrm{g} /$ $\mathrm{ml}$ anti-EGFR antibody cetuximab for $1 \mathrm{~h}$ at $4^{\circ} \mathrm{C}$ followed by Protein $\mathrm{A} / \mathrm{G}$ beads for $1 \mathrm{~h}$ at $4^{\circ} \mathrm{C}$ to remove all EGFR-HER2 and EGFR-EGFR dimers from the lysates. The EGFR-cleared lysates were subjected to Western blot analysis as described above using anti-HER2 antibody Ab10 as a probe. Protein levels in total lysates were detected with anti-HER 2 mAb Ab10 and anti-EGFR mAb Ab11 using Western blot analysis.

Phosphorylation analysis. CAL27, NCI-H226 and NCI-N87 cells were serum starved overnight, washed with cold PBS containing $0.1 \mathrm{mM} \mathrm{Na}_{2} \mathrm{VO}_{4}$ and treated with $20 \mu \mathrm{g} / \mathrm{ml}$ 

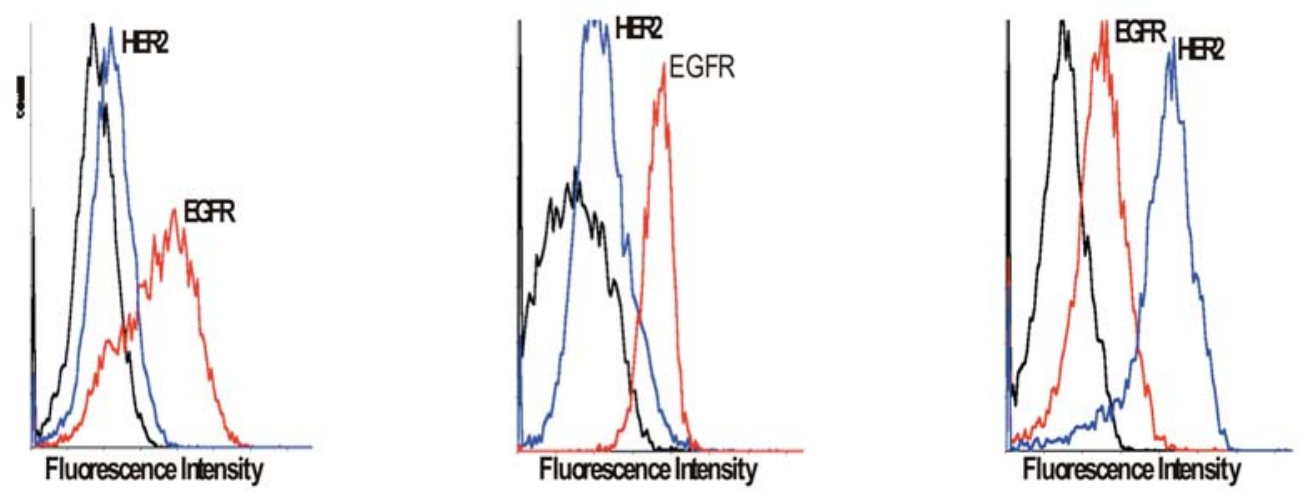

Figure 1. EGFR and HER2 co-express in tumor cell lines. CAL27, NCI-H226 and NCI-N87 cells were stained with control human IgG (black), anti-EGFR antibody cetuximab (red) or anti-HER2 antibody trastuzumab (blue). Cells were washed and labeled with FITC anti-human secondary antibody and analyzed using an Epics XL flow cytometer.

cetuximab or human $\mathrm{IgG}$ for $30 \mathrm{~min}$ at $37^{\circ} \mathrm{C}$, followed by stimulation with $100 \mathrm{ng} / \mathrm{ml} \mathrm{EGF}$ ligand for $10 \mathrm{~min}$ at $37^{\circ} \mathrm{C}$. Cells were washed twice with cold PBS/50 nm Na $2 V_{4}$ and lysed with lysis buffer as described above. Total lysates were separated by SDS-PAGE and transferred to PVDF membranes and probed with phospho-specific anti-EGFR mAb and phospho-specific anti-HER2 mAb (Tyr877 and Tyr1248). For downstream signaling molecules, antibodies to p-AKT (Ser473, Thr308), AKT, p-44/42 ERK 1/2 (Thr202/Tyr204), Erk 1/2 and p-STAT3 (Ser727, Tyr705) were used. Immunoreactive bands were detected via ECL (Amersham Pharmacia Biotech, NJ).

Proliferation assay. Cells were plated at $2 \times 10^{3}$ cells/well in media with $1 \%$ FBS in 96-well flat bottom plates and allowed to adhere. Human IgG, cetuximab, trastuzumab or a combination of cetuximab and trastuzumab were added at $10 \mu \mathrm{g} / \mathrm{ml}$ and diluted down 1:2 in duplicates and incubated for 6-7 days. CellTiter 96 Aqueous One Solution (Promega, WI) $(20 \mu \mathrm{l} /$ well $)$ was added, and plates were read at $490 \mathrm{~nm}$ on an ELISA plate reader (Molecular Devices, CA).

Clonogenic assay. Cells were plated at 2000 cells/well in RPMI-1640 with 10\% FBS in 6-well tissue culture plates and allowed to adhere. Cetuximab, trastuzumab and a combination were added in triplicates at 5,10 and $20 \mu \mathrm{g} / \mathrm{ml}$ and incubated for 10-12 days. Colonies were washed, fixed, stained with Crystal Violet and counted.

Animal studies. Athymic nude mice (Charles River, MA) were injected with $5 \times 10^{6}$ NCI-N87 or $20 \times 10^{6}$ CAL27 cells mixed with 1:1 Matrigel (Collaborative Research Biochemicals, MA). Upon reaching $150-200 \mathrm{~mm}^{3}$ tumors were treated with antibodies as indicated in the figures at $1 \mathrm{mg} / \mathrm{dose} \mathrm{M}-\mathrm{W}-\mathrm{F}$. Measurements were taken twice a week. Tumor volumes were analyzed using the RM ANOVA test. Statistical analyses were computed using the SigmaStat statistical package (version 2.03) (Jandel Scientific, CA).

Histology. Sections (4- $\mu \mathrm{m})$ of formalin fixed, paraffinembedded NCI-N87 tumors treated with cetuximab or control were stained with anti-P-HER2/Y1248 and P-EGFR/Y845 (Cell Signaling Technology) after heat-induced epitope retrieval using the EnVision ${ }^{+}$Rabbit System (Dako, CA) as outlined in the kit instructions. After light counterstaining with Mayer's hematoxylin, dehydration and coverslipping, sections were examined using an Axioskop microscope (Zeiss, NY) and images were digitized using a Sony camera (Sony Corp., TX) and Scion CG-7 framegrabber (Scion Corp., MD).

\section{Results}

EGFR and HER2 co-express in tumor cell lines. EGFR is expressed in a variety of tumor cell lines such as head and neck, colon, lung, pancreatic, ovarian and gastric cancer cell lines. CAL27 (squamous carcinoma), NCI-H226 (non-small cell lung cancer) and NCI-N87 (gastric carcinoma) were found to express EGFR on the cell surface [mean fluorescence intensity (MFI) was 981, 658 and 153 respectively) when cells were analyzed by FACS (Fig. 1). HER2 was reported to be mainly expressed by breast and ovarian cancer cells (7-10). We found that CAL27 and NCI-H226 cells expressed low levels of HER2 (MFI, 30 and 54 respectively), while NCI-N87 expressed high levels of HER2 (MFI, 1514) (Fig. 1).

Cetuximab inhibits the formation of EGFR-EGFR homodimers and EGFR-HER2 heterodimers. Since NCI-N87 cells co-express reasonable amounts of EGFR and HER2, we studied the effect of cetuximab on the dimer formation of EGFR-EGFR, EGFR-HER2 and HER2-HER2 in this cell line (Fig. 2). The receptor dimers were cross-linked with DTSSP as described in Materials and methods. As shown in Fig. 2, cetuximab blocked EGF-induced EGFR-EGFR dimer formation. EGFR-HER2 dimers were detected by immunoprecipitating with cetuximab and probing with anti-HER2 $\mathrm{mAb}$ (Fig. 2). In the presence of cetuximab, the formation of such a dimer was inhibited. On the other hand, cetuximab had no effect on HER2-HER2 dimer formation (Fig. 2). Even in the absence of EGF, HER2-HER2 dimers were detected.

Cetuximab downregulates EGFR and HER2 phosphorylation and downstream signaling events. To further study the effect of cetuximab on receptor activation and the signaling pathway, we measured P-EGFR, P-HER2, P-AKT, P-STAT3 and PMAPK in cetuximab-treated tumor cells (Fig. 3). As expected, cetuximab inhibited EGF-induced EGFR phosphorylation in 
EGFR-EGFR

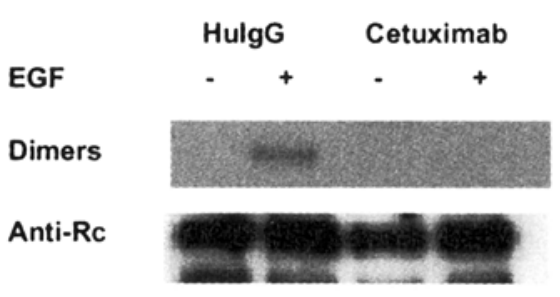

EGFR-HER2

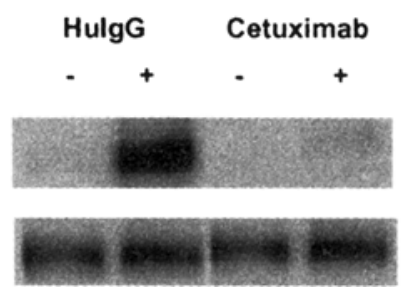

HER2-HER2

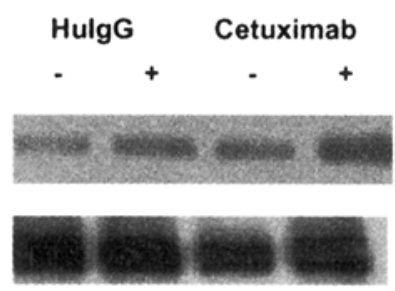

Figure 2. Cetuximab inhibits the formation of EGFR-EGFR homodimers and EGFR-HER2 heterodimers. Serum-starved cells were treated with $20 \mu \mathrm{g} / \mathrm{ml}$ cetuximab or human $\mathrm{IgG}(\mathrm{HuIgG})$ for $30 \mathrm{~min}$ at $37^{\circ} \mathrm{C}$ followed by stimulation with $100 \mathrm{ng} / \mathrm{ml} \mathrm{EGF}$ ligand for $10 \mathrm{~min}$ at $37^{\circ} \mathrm{C}$. Receptors were cross-linked with DTSSP. The dimers were detected as described in Materials and methods. Protein levels were detected with anti-HER2 mAb Ab11 and anti-EGFR mAb Ab10.

CAL 27

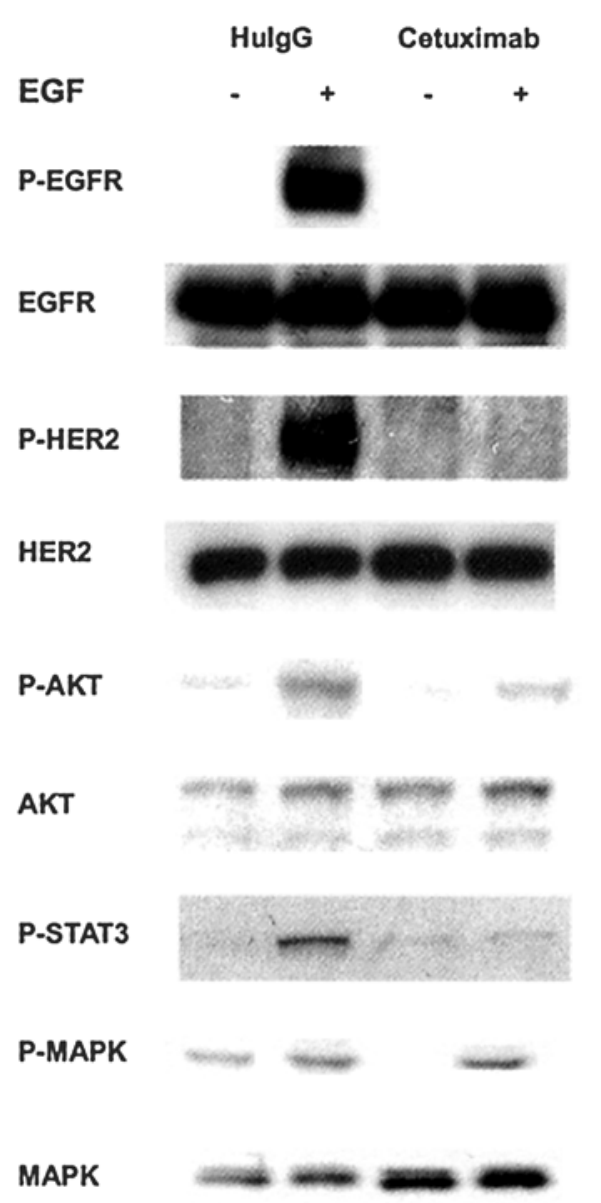

$\mathrm{NCl}-\mathrm{H} 226$
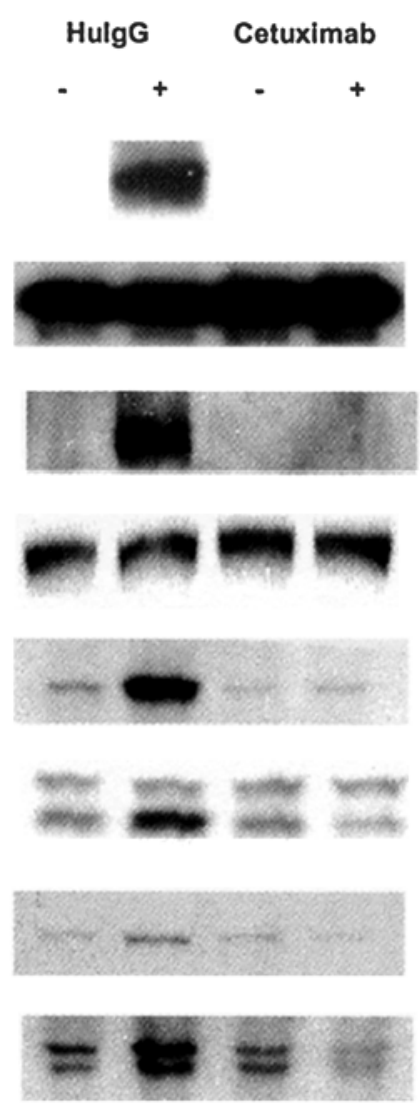

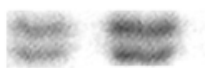

NCl-N87

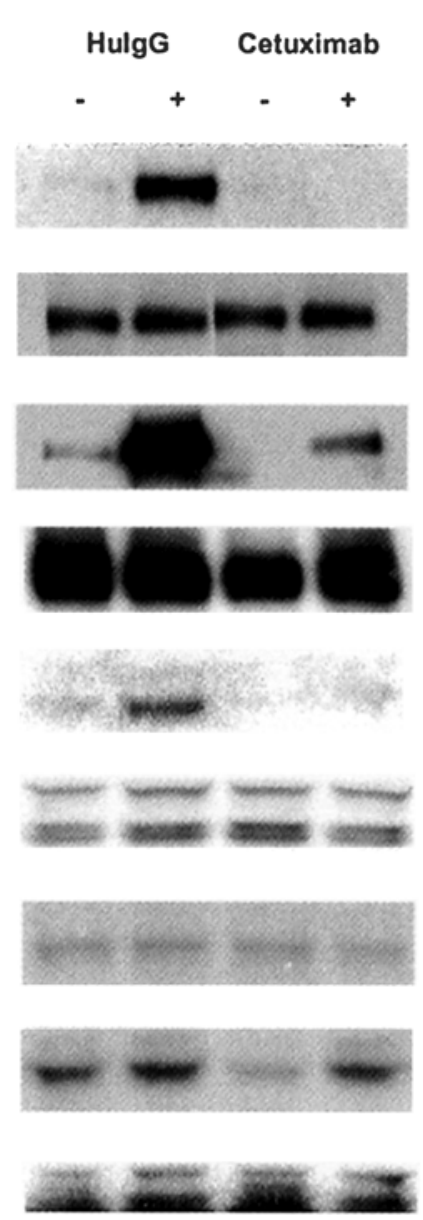

Figure 3. Cetuximab binds EGFR and downregulates EGFR-HER2 activation and downstream signaling events. Phospho-EGFR and phospho-HER2 were detected as described in Materials and methods. Signaling P-AKT (Ser473, Thr308), AKT, P-44/42 ERK 1/2 (Thr202/Tyr204), Erk 1/2 and P-STAT3 (Ser727, Tyr705) were measured. Immunoreactive bands were detected via ECL.

CAL27, NCI-H226 and NCI-N87 cells. EGF-induced HER2 phosphorylation was blocked completely by cetuximab in CAL27 and NCI-H226 cells. HER2 in NCI-HN87 cells underwent autophosphorylation (Fig. 3) slightly, and such phosphorylation was enhanced with EGF stimulation. Cetuximab treatment was able to dramatically reduce the HER2 phosphorylation, but not completely.

AKT activation plays an important role in tumor cell survival $(20,21)$. Both EGFR and HER2 activation can lead to AKT phosphorylation (14). Cetuximab was able to inhibit
AKT phosphorylation in a variety of EGFR-expressing tumor cell lines (23). When we examined the AKT phosphorylation status in cetuximab-treated cell lines, we found that cetuximab was still effective in reducing phospho-AKT (Fig. 3) in these cells. STAT3 is another important signaling molecule in cancer (30). Both EGFR and HER2 activation can induce STAT3 phosphorylation. STAT3 was phosphorylated slightly in CAL27, NCI-H226 and NCI-N87 cells (Fig. 3). EGF enhanced phospho-STAT3 in CAL27 and NCI-H226 cells, but not in NCI-N87 cells. Cetuximab inhibited EGF-induced 
C A L 27
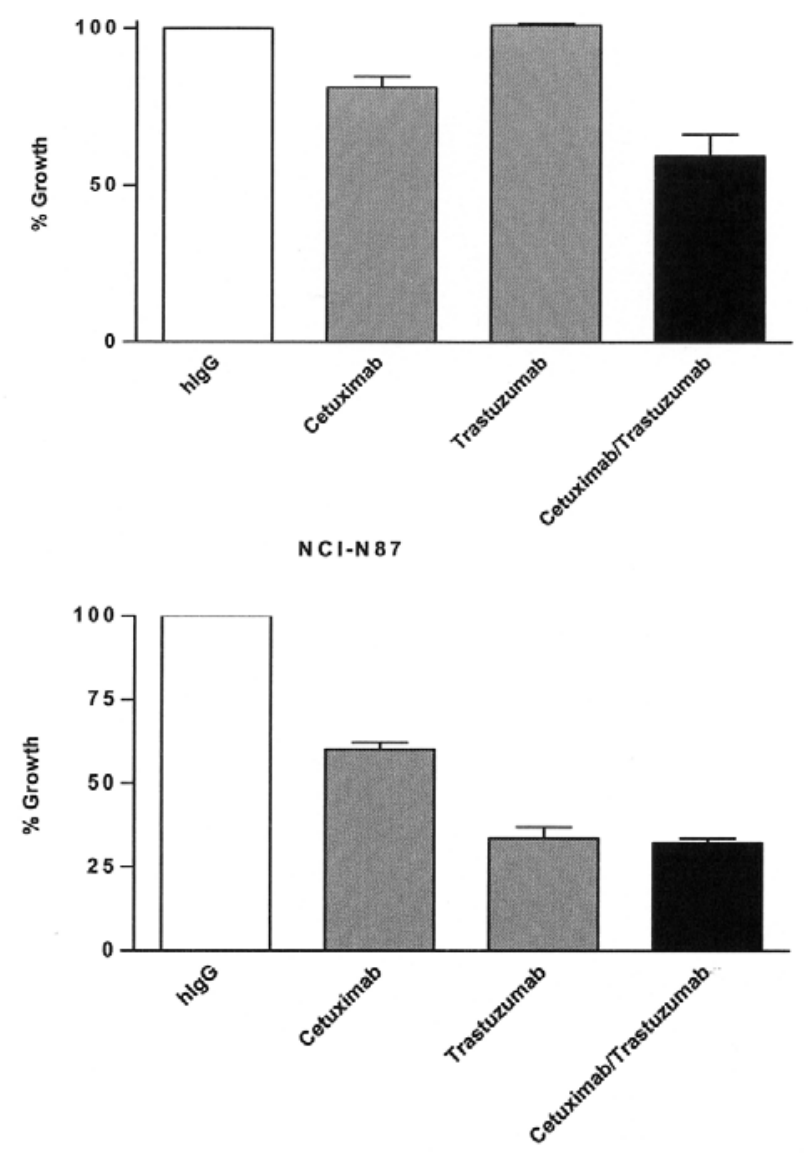

N CI-H 226

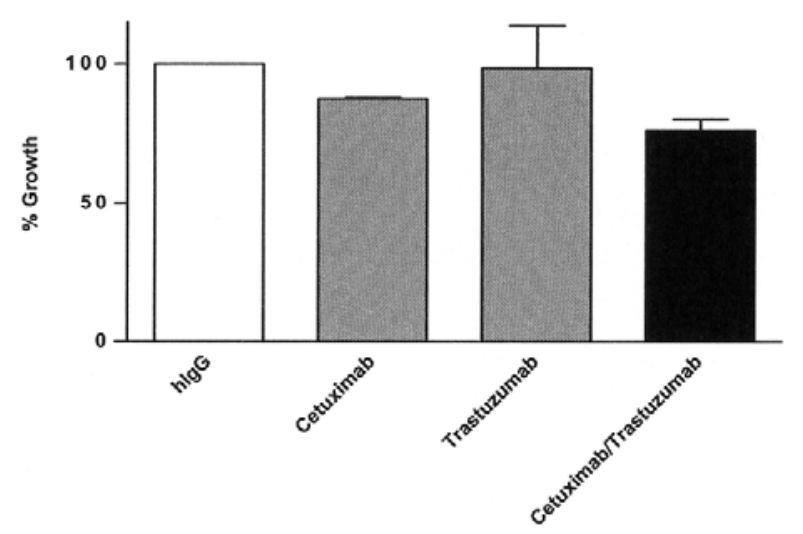

Figure 4. Inhibition of cetuximab and trastuzumab on tumor cell proliferation. Cells were plated in 96-well flat bottom plates and allowed to adhere. Human IgG (hIgG), cetuximab, trastuzumab or a combination of cetuximab and trastuzumab were added at $10 \mu \mathrm{g} / \mathrm{ml}$ in duplicates and incubated for 6 days. CellTiter 96 Aqueous One Solution (20 $\mu 1 /$ well) was added, and plates were read at $490 \mathrm{~nm}$ on an ELISA plate reader. The growth rate of human IgG-treated cells was considered as $100 \%$.

STAT3 phosphorylation in CAL27 and NCI-H226 cells. The basal level of phospho-STAT3 was not affected by cetuximab in all three cell lines (Fig. 3). EGF stimulated MAPK phosphorylation in NCI-H226 cells and had no effect on MAPK activation in CAL27 and NCI-N87 cells. Cetuximab treatment blocked MAPK phosphorylation in NCI-H226 cells (Fig. 3). The basal levels of phospho-MAPK in cells were not changed by cetuximab treatment.
CAL27

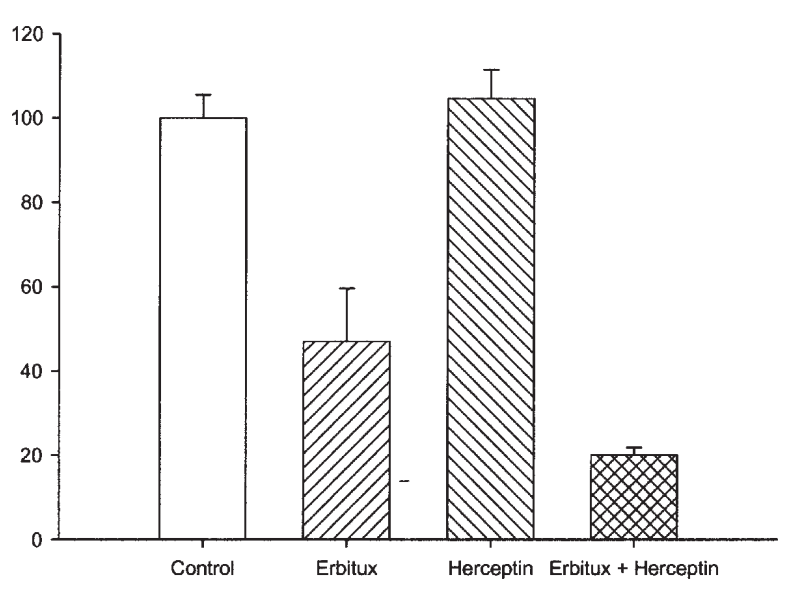

NCI-N87

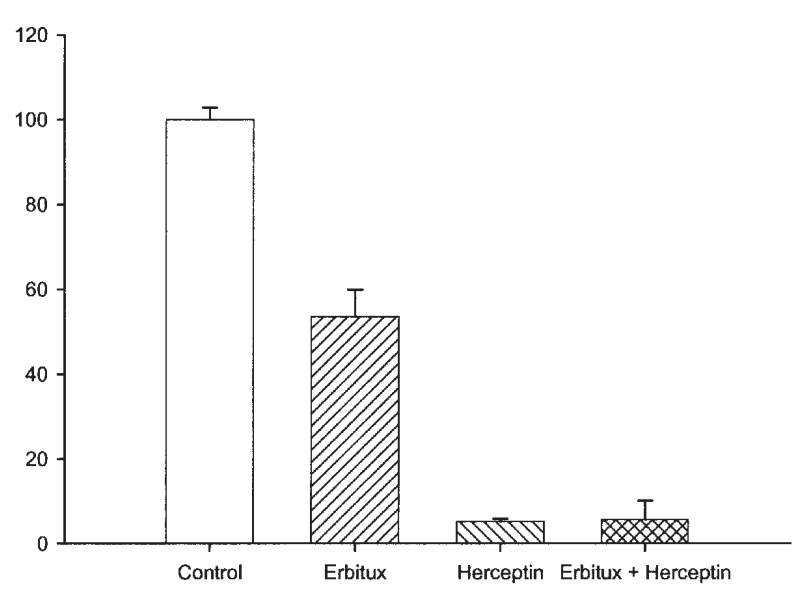

Figure 5. Inhibition of colony formation by cetuximab (Erbitux) and trastuzumab (Herceptin). Cells were plated in 6-well tissue culture plates and allowed to adhere. Cetuximab, trastuzumab or a combination were added in triplicates at $20 \mu \mathrm{g} / \mathrm{ml}$ and incubated for 10-12 days. Colonies were washed, fixed, stained with Crystal Violet and counted. The colony formation rate in human IgG-treated cells was considered as $100 \%$.

Inhibition of colony formation and proliferation by cetuximab and trastuzumab. The effect of cetuximab and trastuzumab on tumor cell growth was evaluated by proliferation and colony formation assays. In proliferation assay, cetuximab was able to inhibit CAL27, NCI-H226 and NCI-N87 cell growth by 19, 30 and $40 \%$ respectively (Fig. 4). Trastuzumab had no effect on CAL27 and NCI-H226 cell growth and inhibited NCI-N87 cell growth by $66 \%$ (Fig. 4). The growth of cells treated with cetuximab plus trastuzumab were inhibited more or equally compared to single agent treatment (Fig. 4). Colony formation assay was performed on CAL27 and NCI-N87 cells. Cetuximab inhibited CAL27 colony formation by 53\% and NCIN87 cell colony formation by $47 \%$ (Fig. 5). Trastuzumab was able to inhibit NCI-N87 cell colony formation by $95 \%$ and had no effect on CAL27 cell colony formation. Combination treatment with cetuximab and trastuzumab inhibited colony formation of CAL 27 by $80 \%$ and NCI-N87 cells by $94 \%$ (Fig. 5). 
A

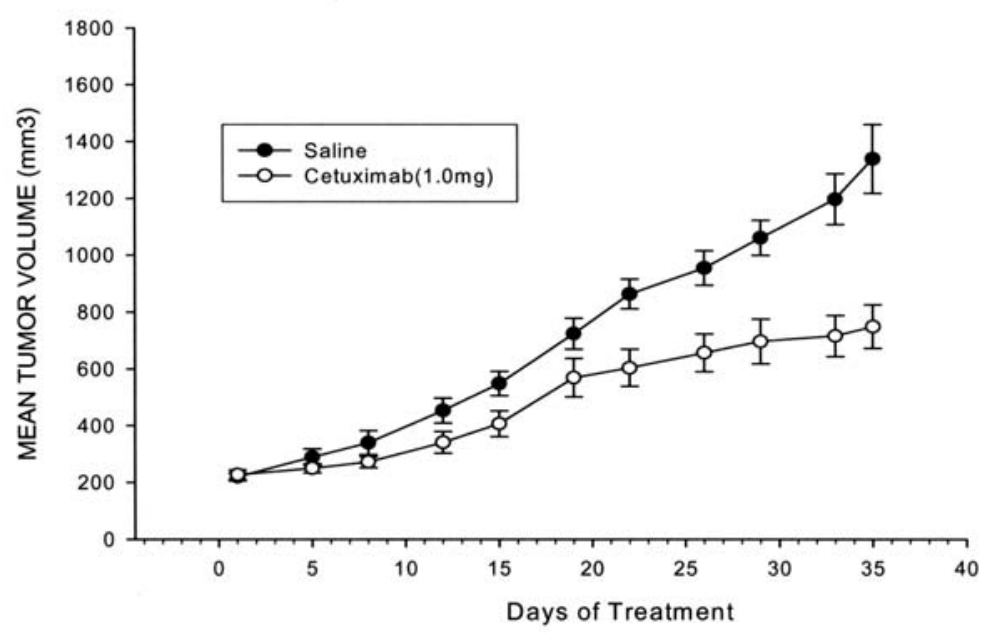

B

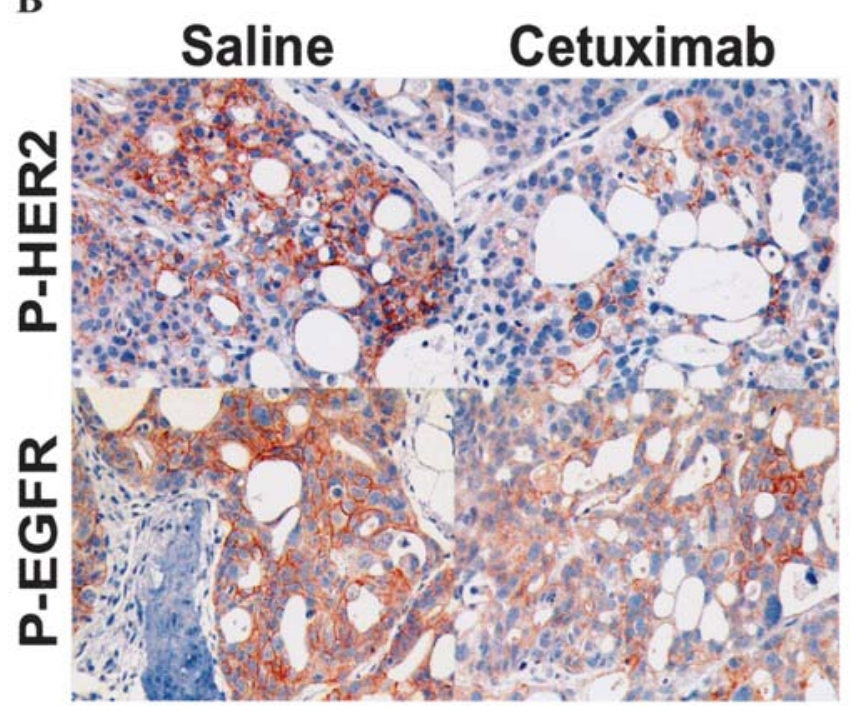

Figure 6. Cetuximab inhibits the growth of NCI-N87 tumors and downregulates EGFR and HER2 phosphorylation in vivo. (A) Athymic nude mice were injected with $5 \times 10^{6} \mathrm{NCI}-\mathrm{N} 87$ cells mixed with 1:1 Matrigel. When the tumor size reached $150-200 \mathrm{~mm}^{3}$, mice were treated with cetuximab or human IgG at $1 \mathrm{mg} /$ dose M-W-F. (B) By the end of the study, tumors were removed, sectioned, and stained with anti-P-HER2/Y1248 and -P-EGFR/Y845.

Cetuximab inhibits the growth of tumors and downregulates EGFR and HER 2 phosphorylation in vivo. To assess the in vivo effect of cetuximab on HER2 phosphorylation, we treated NCI-N87 tumor xenografts in nude mice with cetuximab and examined phospho-HER2 and phospho-EGFR from the tumors (Fig. 6). Cetuximab significantly inhibited the growth of the NCI-N87 xenograft by 44\% (P<0.0001) (Fig. 6A). Histochemical analysis using P-HER2- and P-EGFR-specific $\mathrm{mAb}$ showed that cetuximab reduced the staining of P-HER2 and P-EGFR in tumors (Fig. 6B).

Since CAL27 expresses both EGFR and HER2, we tested the efficacy of cetuximab, trastuzumab or trastuzumab combined with cetuximab in a CAL27 xenograft model (Fig. 7). All three treatment regimes significantly inhibited the growth of CAL27 xenografts. Tumor growths were inhibited $60 \%(\mathrm{P}=0.001)$ by trastuzumab, $92 \%(\mathrm{P}<0.0001)$ by cetuximab and $97 \%(\mathrm{P}<0.0001)$ by combination treatment. By the end of the study (day 50), inhibition of tumor growth by cetuximab or combination therapy was significantly greater than that by trastuzumab alone ( $\mathrm{P}=0.01)$ (Fig. 7). There were no differences in tumor inhibition between mice treated with cetuximab and the combination therapy. Tumor regressions were observed in $100 \%(10 / 10)$ cetuximab-treated, 50\% (5/10) trastuzumabtreated and $100 \%(10 / 10)$ combination therapy-treated mice (Chi-square test, $\mathrm{P}<0.0001)$.

\section{Discussion}

Since HER2 lacks a ligand binding domain, it is activated by co-expressing and forming heterodimers with other members of the ErbB family. EGFR and HER2 are co-expressed more often in tumors than other members of the ErbB family, implicating that EGFR plays an important role in HER2 activation. It has been shown that EGF can induce the formation of EGFR/Neu (HER2) heterodimers in PC rat cells (31). Such heterodimers were detected in vivo (32), and the basal phosphorylation of EGFR and HER2 was increased in cells transfected with EGFR and HER2 (33). Moreover, EGFR 


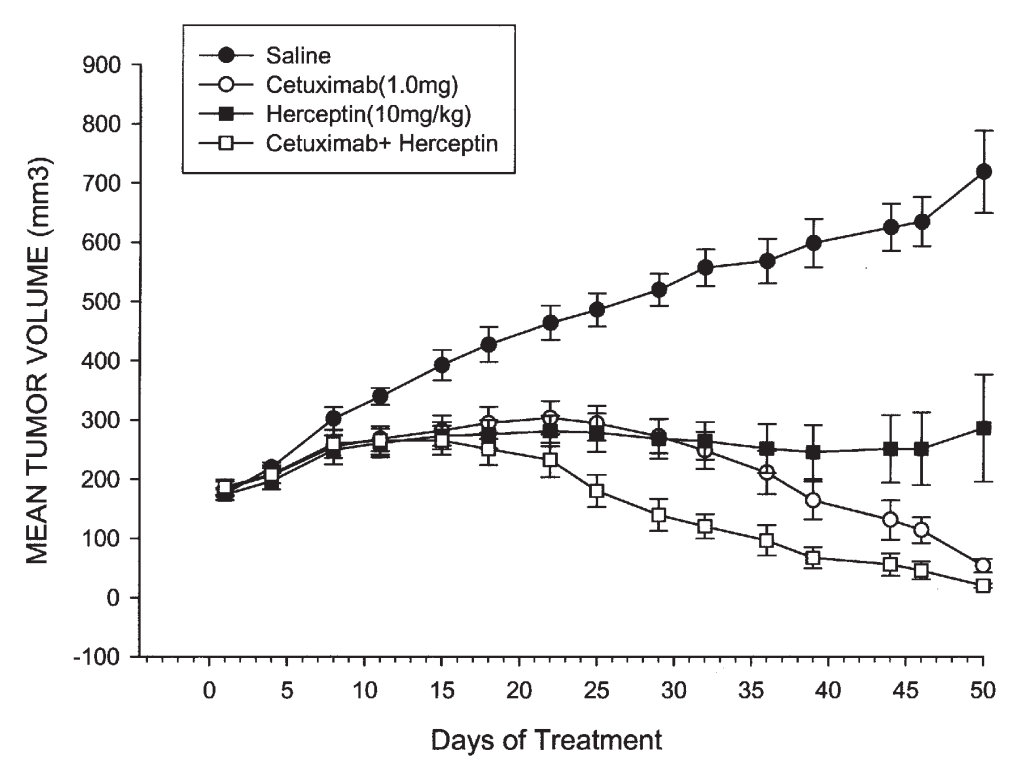

Figure 7. Cetuximab inhibits the growth of CAL27 tumors. CAL27 cells were injected subcutaneously (s.c.) into the flank regions of athymic nude mice. Antibodies were administered intraperitoneally (i.p.) starting after tumor sizes reached $200 \mathrm{~mm}^{3}$. Mice bearing CAL27 tumors were treated with human IgG $(\bullet)$, cetuximab $(\odot)$, Herceptin $(\bullet)$ and cetuximab plus Herceptin $(\square)$. There were 10 mice in each group. Points, means; bars, SE.

inhibitors were able to inhibit the growth of HER2- and TGF- $\alpha$-driven tumors (34), and cetuximab enhanced the antitumor efficacy of anti-HER2 mAbs (35). These findings suggest that HER2 activation requires EGFR/HER2 heterodimer formation.

Cetuximab is able to block EGF-induced EGFR phosphorylation and activation. The binding domain of cetuximab on EGFR was not known until recently. Cetuximab binds exclusively to domain III, overlapping the epitopes to which EGF binds on domain III (27). EGF binds to domain I and III on EGFR and has no contact between the two EGFs in the dimeric complex $(36,37)$. Recent studies have shown that once EGF binds to domain I and domain III, it alters the spatial arrangement of domains within EGFR (38). The normally buried domain II and domain IV become exposed and form a dimerization contact arm. This rearranged conformation preferentially favors dimeric structure. Cetuximab blocks the formation of such a rearranged (extended) EGFR and therefore inhibits EGFR-EGFR dimer formation. The HER2 structural configuration is little different from EGFR. Without ligand binding, HER2 can keep an extended configuration similar to EGFR conformation induced by EGF. Therefore, HER2 can readily form a heterodimer with the EGF-stabilized EGFR.

EGFR/HER2 heterodimerization can trigger a cascade of signaling events. It is difficult to determine which pathways are important in specific cell lines, but the AKT and MAPK pathways are considered the most relevant for oncogenic activity of the ErbB family. The activation of MAPK activates cyclin D1, a protein required for cell cycle progression from G1 to $\mathrm{S}$ phase and therefore promotes tumor cell proliferation and division. The AKT pathway influences cell survival and plays an important role in the resistance to apoptosis. Our data demonstrated that both pathways can be inhibited by cetuximab (Fig. 3).

STAT3 is another important signaling molecule that plays a critical role in malignant transformation and progression. It has been reported that EGF can activate members of STAT, including STAT1 and STAT3. We found that EGF induced STAT3 phosphorylation in CAL27 and NCI-H226 cells, and cetuximab was able to block this phosphorylation. There was some basal STAT3 phosphorylation in CAL27, NCI-N87 and NCI-H226 cells, but this was not affected by cetuximab. It remains unknown why the EGF was able to induce EGFR and HER2 phosphorylation in NCI-N87 cells while having no effect on STAT3 phosphorylation.

Cetuximab inhibited tumor cell growth in the proliferation and colony formation assays. This inhibition seemed to be related to the inhibition of phosphorylation of EGFR by cetuximab (Fig. 3). Cetuximab completely blocked EGFinduced EGFR phosphorylation and inhibited cell growth ranging from 19 to $40 \%$ in the proliferation assay, suggesting that cell growth dependent on the EGFR pathway varies. Trastuzumab also inhibited the growth of NCI-H226 and NCI-N87 cells in vitro, but had no effect on CAL27 cells. The growth inhibition by trastuzumab correlated with HER2 expression on cell surfaces (Figs. 1,4 and 5). Trastuzumab and cetuximab both inhibited tumor growth in vivo. Although trastuzumab had no effect on the growth of CAL27 in vitro, it had significant inhibitory effect on tumor growth in vivo (Fig. 7). Trastuzumab inhibits tumor growth by multiple mechanisms. Activation of effector cells is one of the mechanisms that have been suggested by Clynes et al (39). The antitumor effect of trastuzumab in Fc receptor-deficient mice was drastically reduced. Moreover, trastuzumab engineered to disrupt $\mathrm{Fc}$ receptor binding did not arrest tumor growth in vivo, suggesting that $\mathrm{Fc}$ receptor expressing effector cells may play an important role in the efficacy of trastuzumab.

In summary, we demonstrated that cetuximab inhibits EGFR-EGFR homodimerization and EGFR-HER2 heterodimerization, receptor phosphorylation and subsequent signaling cascades. The in vitro and in vivo tumor growth 
was also inhibited by cetuximab. Since some tumors express both EGFR and HER2, this finding has significant clinical relevance. It suggests that cetuximab may be used to treat patients with tumors expressing EGFR and HER2.

\section{References}

1. Olayioye MA, Neve RM, Lane HA and Hynes NE: The ErbB signaling network: receptor heterodimerization in development and cancer. EMBO J 19: 3159-3167, 2000.

2. Jardines L, Weiss M, Fowble B and Greene M: neu(c-erbB-2/ HER2) and the epidermal growth factor receptor (EGFR) in breast cancer. Pathobiology 61: 268-282, 1993.

3. Mendelsohn J: Targeting the epidermal growth factor receptor for cancer therapy. J Clin Oncol 20 (Suppl 18): 1-13, 2002.

4. Di Fiore PP, Pierce JH, Fleming TP, Hazan R, Ullrich A, King CR, Schlessinger J and Aaronson SA: Overexpression of the human EGF receptor confers an EGF-dependent transformed phenotype to NIH 3T3 cells. Cell 51: 1063-1070, 1987.

5. Valverius EM, Bates SE, Stampfer MR, Clark R, McCormick F, Salomon DS, Lippman ME and Dickson RB: Transforming growth factor alpha production and epidermal growth factor receptor expression in normal and oncogene transformed human mammary epithelial cells. Mol Endocrinol 3: 203-214, 1989.

6. Ekstrand AJ, Sugawa N, James CD and Collins VP: Amplified and rearranged epidermal growth factor receptor genes in human glioblastomas reveal deletions of sequences encoding portions of the N-and/or C-terminal tails. Proc Natl Acad Sci USA 89: 4309-4313, 1992.

7. Noguchi M, Koyasaki N, Ohta N, Kitagawa H, Earashi M, Thomas M, Miyazaki I and Mizukami Y: Internal mammary nodal status is a more reliable prognostic factor than DNA ploidy and c-erb B2 expression in patients with breast cancer. Arch Surg 128: 242-246, 1993.

8. Midulla C, Giovagnoli MR, Valli C and Vecchione A: Correlation between ploidy status, ERB-B2 and P53 immunohistochemical expression in primary breast carcinoma. Anal Quant Cytol Histol 17: 157-162, 1995.

9. Eissa S, Khalifa A, El-Gharib A, Salah N and Mohamed MK: Multivariate analysis of DNA ploidy, p53, c-erbB-2 proteins, EGFR, and steroid hormone receptors for short term prognosis in breast cancer. Anticancer Res 17: 3091-3098, 1997.

10. Tiwari RK, Borgen PI, Wong GY, Cordon-Cardo C and Osborne MP: HER-2/neu amplification and overexpression in primary human breast cancer is associated with early metastasis. Anticancer Res 12: 419-426, 1992.

11. Klapper LN, Kircschbaum MH, Sela M and Yarden Y: Biochemical and clinical implications of the ErbB/HER signaling network of growth factor receptors. Adv Cancer Res 1: 25-79, 2000.

12. Simpson BJ, Phillips HA, Lessels AM, Langdon SP and Miller WR: c-erbB growth-factor-receptor proteins in ovarian tumours. Int J Cancer 64: 202-206, 1995.

13. Klapper LN, Glathe S, Vaisman N, Hynes NE, Andrews GC, Sela M and Yarden Y: The ErbB-2/HER2 oncoprotein of human carcinomas may function solely as a shared coreceptor for multiple stroma-derived growth factors. Proc Natl Acad Sci USA 96: 4995-5000, 1999.

14. Alroy I and Yarden Y: The ErbB signaling network in embryogenesis and oncogenesis: signal diversification through combinatorial ligand-receptor interactions. FEBS Lett 410: 83-86, 1997.

15. Burden S and Yarden Y: Neuregulins and their receptors: a versatile signaling module in organogenesis and oncogenesis. Neuron 18: 847-855, 1997.

16. Stern DF and Kamps MP: EGF-stimulated tyrosine phosphorylation of p185neu: a potential model for receptor interactions. EMBO J 7: 995-1001, 1988.

17. Lewis TS, Shapiro PS and Ahn NG: Signal transduction through MAP kinase cascades. Adv Cancer Res 74: 49-139, 1998.

18. Liu W, Li J and Roth RA: Heregulin regulation of Akt/protein kinase B in breast cancer cells. Biochem Biophys Res Commun 261: 897-903, 1999.

19. Muthuswamy SK, Gilman M and Brugge JS: Controlled dimerization of erbB receptors provides evidence for differential signalling by homo- and heterodimers. Mol Cell Biol 19: 6845$6857,1999$.
20. Burgering BM and Coffer PJ: Protein kinase B (c-Akt) in phosphatidylinositol-3-OH kinase signal transduction. Nature 376: 599-602, 1995.

21. Chan TO, Rittenhouse SE and Tsichlis PN: AKT/PKB and other D3 phosphoinositide-regulated kinases: kinase activation by phosphoinositide-dependent phosphorylation. Ann Rev Biochem 68: 965-1014, 1999.

22. Goldstein NI, Prewett M, Zuklys K, Rockwell P and Mendelsohn J: Biological efficacy of a chimeric antibody to the epidermal growth factor receptor in a human tumor xenograft model. Clin Cancer Res 11: 1311-1318, 1995.

23. De Bono JS and Rowinsky EK: Therapeutics targeting signal transduction for patients with colorectal carcinoma. Br Med Bull 64: 227-254, 2002.

24. Giaccone G: Epidermal growth factor receptor inhibitors in the treatment of non-small-cell lung cancer. J Clin Oncol 23: 3235-3242, 2005.

25. Prewett MC, Hooper AT, Bassi R, Ellis LM, Waksal HW and Hicklin DJ: Enhanced antitumor activity of anti-epidermal growth factor receptor monoclonal antibody IMC-C225 in combination with irinotecan (CPT-11) against human colorectal tumor xenografts. Clin Cancer Res 8: 994-1003, 2002.

26. Huang SM, Bock JM and Harari PM: Epidermal growth factor receptor blockade with $\mathrm{C} 225$ modulates proliferation, apoptosis, and radiosensitivity in squamous cell carcinomas of the head and neck. Cancer Res 59: 1935-1940, 1999.

27. Li S, Schmitz KR, Jeffrey PD, Wiltzius JJ, Kussie P and Ferguson KM: Structural basis for inhibition of the epidermal growth factor receptor by cetuximab. Cancer Cell 7: 301-311, 2005.

28. Cobleigh MA, Vogel CL, Tripathy D, Robert NJ, Scholl S, Fehrenbacher L, Wolter JM, Paton V, Shak S, Lieberman G and Slamon DJ: Multinational study of the efficacy and safety of humanized anti-HER2 monoclonal antibody in women who have HER2-overexpressing metastatic breast cancer that has progressed after chemotherapy for metastatic disease. J Clin Oncol 17: 2639-2648, 1999.

29. Baselga $\mathbf{J}$ and Albanell J: Mechanism of action of anti-HER2 monoclonal antibodies. Ann Oncol 12 (Suppl 1): 35-41, 2001.

30. Buettner R, Mora LB and Jove R: Activated STAT signaling in human tumors provides novel molecular targets for therapeutic intervention. Clin Cancer Res 8: 945-954, 2002.

31. Gamett D, Pearson G, Cerione R and Friedberg I: Secondary dimerization between members of the epidermal growth factor receptor family. J Biol Chem 272: 12052-12056, 1997.

32. Tzahar E, Waterman H, Chen X, Levkowitz G, Karunagaran D, Lavi S, Ratzkin BJ and Yarden Y: A hierarchical network of interreceptor interactions determines signal transduction by $\mathrm{Neu}$ differentiation factor/neuregulin and epidermal growth factor. Mol Cell Biol 16: 5276-5287, 1996.

33. Riese DJ, van Raaij TM, Plowman GD, Andrews GC and Stern DF: The cellular response to neuregulins is governed by complex interactions of the erbB receptor family. Mol Cell Biol 15: 5770-5776, 1995.

34. Lenferink AE, Simpson JF, Shawver LK, Coffey RJ, Forbes JT and Arteaga CL: Blockade of the epidermal growth factor receptor tyrosine kinase suppresses tumorigenesis in MMTV/ $\mathrm{Neu}^{+}$MMTV/TGF- $\alpha$ bigenic mice. Proc Natl Acad Sci USA 97: 9609-9614, 2000

35. Ye D, Mendelsohn J and Fan Z: Augmentation of a humanized anti-HER $2 \mathrm{mAb}$ 4D5 induced growth inhibition by a humanmouse chimeric anti-EGF receptor $\mathrm{mAb} C 225$. Oncogene 18: 731-738, 1999.

36. Garrett TPJ, McKern NM, Lou M, Elleman TC, Adams TE, Lovrecz GO, Zhu H-J, Walker F, Frenkel MJ, Hoyne PA, et al: Crystal structure of a truncated epidermal growth factor receptor extracellular domain bound to transforming growth factor alpha. Cell 110: 763-773, 2002.

37. Ogiso H, Ishitani R, Nureki O, Fukai S, Yamanaka M, Kim JH, Saito K, Sakamoto A, Inoue M and Shirouzu M: Crystal structure of the complex of human epidermal growth factor and receptor extracellular domains. Cell 110: 775-787, 2002.

38. Burgess AW, Cho HS, Eigenbrot C, Ferguson KM, Garrett TP, Leahy DJ, Lemmon MA, Sliwkowski MX, Ward CW and Yokoyama S: An open-and-shut case? Recent insights into the activation of EGF/ErbB receptors. Mol Cell 12: 541-552, 2002.

39. Clynes RA, Towers TL, Presta LG and Ravetch JV: Inhibitory $\mathrm{Fc}$ receptors modulate in vivo cytoxicity against tumor targets. Nat Med 6: 443-446, 2000. 